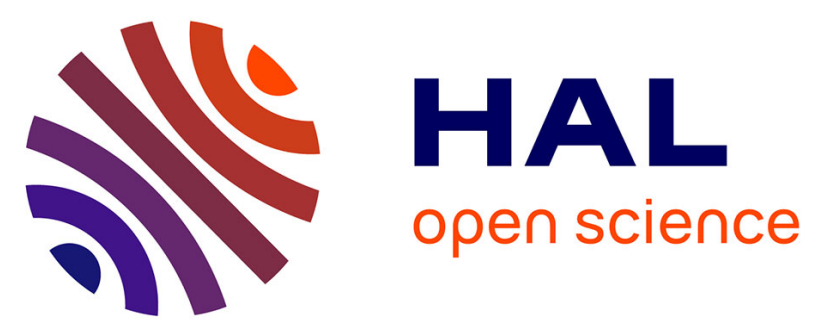

\title{
Personalizing Patients' Advance Directives Decreases the Willingness of Intensive Care Unit Residents to Stop Treatment: A Randomized Study
}

Stéphane Jouffre, Joanne Ghazal, René Robert, Jean Reignier, Dolores Albarracín

\section{To cite this version:}

Stéphane Jouffre, Joanne Ghazal, René Robert, Jean Reignier, Dolores Albarracín. Personalizing Patients' Advance Directives Decreases the Willingness of Intensive Care Unit Residents to Stop Treatment: A Randomized Study. Journal of Palliative Medicine, 2018, 21 (8), pp.1157-1160. 10.1089/jpm.2017.0502 . hal-02146682

\section{HAL Id: hal-02146682 \\ https://hal.science/hal-02146682}

Submitted on 4 Jun 2019

HAL is a multi-disciplinary open access archive for the deposit and dissemination of scientific research documents, whether they are published or not. The documents may come from teaching and research institutions in France or abroad, or from public or private research centers.
L'archive ouverte pluridisciplinaire $\mathbf{H A L}$, est destinée au dépôt et à la diffusion de documents scientifiques de niveau recherche, publiés ou non, émanant des établissements d'enseignement et de recherche français ou étrangers, des laboratoires publics ou privés. 


\title{
Personalizing Patients' Advance Directives Decreases the Willingness of Intensive Care Unit Residents to Stop Treatment: A Randomized Study
}

\author{
Stéphane Jouffre, $\mathrm{PhD}$, Joanne Ghazal, MPsych, René Robert, MD, PhD, \\ Jean Reignier, $\mathrm{MD}, \mathrm{PhD}^{3}$, and Dolores Albarracín, $\mathrm{PhD}^{4}$
}

\begin{abstract}
Background: While following patients' advance directives (ADs) is legally binding, French physicians in Intensive Care Unit (ICU) perceive them as complicating their decision. Decision making and ICU residents benefit from personalizing the dying process. In France, ADs can include personal information.

Objective: Whether personalizing ADs affects ICU residents' decisions and perception of the patient.

Subjects and Design: Sixty-six ICU residents assigned to three experimental groups and presented with a case file for an ICU patient. The files were identical except for the patient's AD, which was manipulated to give three conditions: No Personal Information, Sociodemographic Information, and Agency Information (ability to plan and act upon the world).

Measurements: Residents evaluated the relevance of the AD, assessed its influence on medical decisions, and decided whether to stop treatment, postpone the decision, or consult the family. Finally, they evaluated the patient with respect to two dimensions of personhood (agency and experience).

Results: Residents in all conditions considered the AD to be highly relevant and influential. Residents in both Information conditions perceived the patient as having more capacities for agency and for experience than those in the No Information condition. They were also less likely to stop treatment and more likely to postpone their decision. Consulting the family was not sensitive to the information condition.

Conclusion: Personalizing ADs of an unknown patient leads ICU residents to be less prone to follow them, but does not affect whether or not they decide to consult the patient's family. Hence, promoting shared decision making by including the incapacitated patients' families in treatment decisions is a major challenge, especially in countries such as France, where ADs are legally binding.
\end{abstract}

Keywords: advance directives; intensive care unit; personalization; randomized study; social perception

\section{Introduction}

A DVANCE Directives (ADs) enable patients to express their preferences about limiting or discontinuing treatments if they become incapacitated and incapable of making such decisions. Since February 2016, physicians in France have had a legal duty to apply ADs, except in emergency situations, ${ }^{1}$ even if fewer than $3 \%$ of French people draw up an $\mathrm{AD}^{2,3}$ Decisions about whether withhold or withdraw treatment are made collegially by the attending physician, an external physician, and Intensive Care Unit (ICU) staff. If ICU physicians feel that a patient's AD does not apply to the medical situation, the patient's family/designated surrogate is automatically included in these decisions. However, if the

\footnotetext{
${ }^{1}$ Centre de Recherches sur la Cognition et l'Apprentissage (UMR CNRS 7295), Centre National de la Recherche Scientifique, Université de Poitiers, Université François Rabelais de Tours, Poitiers, France.

${ }^{2}$ Centre d'Investigation Clinique (Inserm CIC 1402), Institut National de la Santé et de la Recherche Médicale, Centre Hospitalier Universitaire de Poitiers, Université de Poitiers, Poitiers, France.

${ }^{3}$ Médecine Intensive Réanimation, Centre Hospitalier Universitaire de Nantes, Université de Nantes, Nantes, France.

${ }^{4}$ Clinique de l'Acte et Psycho-Sexualité (EA 4050), Université de Poitiers, Poitiers, France.

Accepted January 22, 2018.
} 
AD does apply, the recent law making ADs binding means there are no set rules about including the patient's family. The present study examined the decisions French ICU residents make in this latter circumstance.

French ICU physicians, who rarely know patients before they are admitted, have been shown to express frequent doubts about patients' abilities to fully understand the medical situations for which their ADs were drawn up. ${ }^{4}$ These doubts may be a factor, among several others, in physicians failing to respect ADs. ${ }^{5,6}$ Humanizing end-of-life care ${ }^{7,8}$ by counteracting the effects of nonfunctional and functional causes of depersonalization ${ }^{9-19}$ can remove some of these factors and benefit ICU residents by helping them perceive care as shifting rather than stopping, see patients as individuals, and take into account their families' wishes. ${ }^{7,8}$ Interestingly, ADs may include personal information capable of humanizing patients (e.g., information about sociodemographic status, family, or values), but there is no legal requirement for them to do so. ${ }^{1}$ Giving such information may result in patients being attributed greater personhood in terms of their capacities for agency (ability to control, plan, and act upon the world) and experience (ability to feel emotions, such as joy and fear, and sensations, such as hunger), and as having more inalienable human rights. ${ }^{11,20}$

The present study investigated whether personal information included in an unknown and incapacitated patient's AD impacts ICU residents' decisions to apply the $\mathrm{AD}$, as required by French law, or to consult the patient's family before making a decision. We also assessed whether including personal information in an $\mathrm{AD}$ shapes ICU residents' perceptions of the patient as possessing capacities for agency and experience.

\section{Materials and Methods}

\section{Participants and design}

Participants were 66 ICU residents $\left(30\right.$ females, $M_{\text {age }}=$ 28.3, $\mathrm{SD}=2.6$ ) with at least six months' intensive care experience. All participants consented in writing to take part. Each resident was randomly assigned to one of three conditions in a three (Personal information: No, Sociodemographic, Agency) between-participants design. We excluded data for nine participants because they failed to follow the instructions.

\section{Procedure, material, and manipulation}

Residents individually answered a questionnaire relating to a 72-year-old male patient who had been admitted to an ICU following a resuscitated cardiac arrest. The case details, which included the patient's medical history and day-7 assessment, were designed to suggest, although inconclusively, a poor neurological prognosis.

Residents then read one of three versions of the patient's AD. In the No Information condition $(n=21)$, the AD did not include any personal information. In the Sociodemographic Information condition $(n=19)$, the AD gave the patient's profession, marital status, and number of children. In the Agency Information condition $(n=17)$, the AD included the statement: "Aware of the moral problems and dilemmas raised by my decision, I have written my $\mathrm{AD}$ to express my wishes while I am still able to control, think about, and plan my end of life.' In all three conditions, the patient expressed the desire not to be kept alive artificially or be resuscitated if he were to suffer major brain damage, and stated that this decision had been taken in consultation with his family doctor. The case information and the wishes expressed in the patient's AD were designed to be similar to actual cases admitted to ICUs.

\section{Measures}

Participants indicated on 7-point scales $(-3$, not at all, to 3 , completely) the AD's relevance to this medical situation and whether it should be taken into account when making medical decisions. They then had to imagine they were in a staff meeting and to choose whether to stop treatment, consult the family (either to confirm the patient's wishes, or to decide which decision to take), or postpone the decision. Finally, participants rated the patient's capacity for Agency (7 items, e.g., "making plans and working toward goals") and Experience (11 items, e.g., "feeling afraid or fearful") by completing the validated Dimensions of Mind Perception questionnaire. ${ }^{17,19}$ All items were rated on 7-point scales (-3, not at all, to 3, completely). The reliability of both scales (Cronbach's $\alpha=0.96$ ) was similar to that found in previous studies. ${ }^{19}$ Finally, participants stated their age, gender, and the name of their hospital, and were debriefed.

\section{Results}

Because our measures (evaluations of the AD's relevance, influence of the AD on decisions, Agency, and Experience) were not normally distributed, we performed Kruskal-Wallis analyses of variance with personal information condition as the independent variable. We analyzed the contingency table between personal information condition and the residents' decisions to reveal any links between these two variables. Descriptive statistics are shown in Table 1.

First, the residents in all three conditions considered the AD to be highly relevant to the case $(H(2, N=57)=0.66$, $\left.p=0.717, E_{R}^{2}=0.012\right)$ and that it should be taken into account when making medical decisions $(H(2, N=57)=0.22$, $\left.p=0.896, E_{R}^{2}=0.004\right)$. Second, the decision to stop treatment, postpone the decision, or consult the family depended on personal information condition (two-sided Fisher's exact test: $p=0.005)$. There were no significant differences between the three choices in the No Information condition $(95 \%$ confidence intervals [CIs] for the differences between percentages: $[-0.396,0.396],[-0.060,0.631],[-0.060,0.631])$, whereas in both Information conditions more residents chose to postpone their decision than to stop treatment (95\% CIs [0.021, 0.926], [0.042, 0.898]). Differences between these two decisions and consulting the family were not significant (95\% CIs [ $-0.327,0.221],[-0.875,0.033]$, [-0.720, 0.014], $[-0.582,0.347])$. Hence, compared with the No Information condition, residents in both Information conditions were significantly more likely to postpone their decision and less likely to stop treatment $\left(Z s>1.866, p s<0.061, r^{2} s>0.087\right)$, and did so to a similar extent $\left(Z s<0.944, p s>0.347, r^{2} s<0.025\right)$. There was no difference across the three conditions in the likelihood of consulting the family ( $\left.Z s<1.470, p s>0.142, r^{2} s<0.054\right)$.

Finally, the information condition affected the indices for both Agency $\left(H(2, N=57)=7.63, p=0.022, E_{R}^{2}=0.136\right)$ and Experience $\left(H(2, N=57)=6.59, p=0.037, E_{R}^{2}=0.112\right)$. Compared with residents in the No Information condition, residents in both Information conditions attributed higher Agency $\left(U s<112.00, Z s>1.95, p s<0.051, r^{2} s>0.100\right)$ and Experience $\left(U_{\mathrm{s}}<102.00, Z \mathrm{~s}>2.64, p \mathrm{~s}<0.008, r^{2} \mathrm{~s}>0.174\right)$ to 
Table 1. Descriptive Statistics of the Different Measures According to Information Condition

\begin{tabular}{|c|c|c|c|}
\hline Condition & No information & $\begin{array}{c}\text { Sociodemographic } \\
\text { information }\end{array}$ & $\begin{array}{c}\text { Agency } \\
\text { information }\end{array}$ \\
\hline Measures & $\mathrm{n}=21$ & $\mathrm{n}=19$ & $\mathrm{n}=17$ \\
\hline Relevance of the AD to the case (from -3 to 3 ) & $M d n=2.00$ & $M d n=3.00$ & $M d n=2.00$ \\
\hline Influence of the $A D$ on medical decisions (from -3 to 3 ) & $M d n=2.00$ & $M d n=2.00$ & $M d n=2.00$ \\
\hline \multicolumn{4}{|l|}{ Decision advocated in staff meeting } \\
\hline Stop treatment & $n=9(43 \%)$ & $n=3(16 \%)$ & $n=1(6 \%)$ \\
\hline Consult the family & $n=9(43 \%)$ & $n=4(21 \%)$ & $n=7(41 \%)$ \\
\hline Determine which decision to take & $n=6(29 \%)$ & $n=3(16 \%)$ & $n=6(35 \%)$ \\
\hline Confirmation of the patient's wishes & $n=3(14 \%)$ & $n=1(5 \%)$ & $n=1(6 \%)$ \\
\hline Postpone the decision & $n=3(14 \%)$ & $n=12(63 \%)$ & $n=9(53 \%)$ \\
\hline Perception of patient's agency (from -3 to 3 ) & $M d n=-1.00$ & $M d n=1.57$ & $M d n=1.57$ \\
\hline Perception of patient's experience (from -3 to 3 ) & $M d n=-0.45$ & $M d n=2.00$ & $M d n=1.54$ \\
\hline
\end{tabular}

$\mathrm{AD}$, advance directive.

the patient, and did so to a similar extent $(U \mathrm{~s}>156.00$, $\left.\mathrm{Zs}<0.17, p \mathrm{~s}>0.86, r^{2} \mathrm{~s}<0.001\right)$.*

\section{Discussion}

Our randomized study based on a vignette about an incapacitated patient with a poor but inconclusive neurological prognosis following a resuscitated cardiac arrest showed that including sociodemographic or agency information in an $\mathrm{AD}$ affects residents' decisions. Providing such information made residents less likely to stop treatment and more likely to postpone making a decision, but did not affect whether or not they decided to consult the patient's family. Personal information also increased the residents' perceptions of the patient as being capable of agency and experience. This last point is in line with research on social perception. ${ }^{11,20}$

Perceiving others as possessing human capacities, such as agency and experience, increases feelings of familiarity and proximity. ${ }^{21-23}$ Increasing either social or physical proximity strengthens bonds with family and one's hometown ${ }^{24}$ and reduces the likelihood that people will harm each other. ${ }^{25}$ Providing personal information may have increased the social proximity between resident and patient and thereby made the residents more reluctant to let the patient die by stopping treatment.

One limitation of our study is the absence from our fictional case of the stress and workload factors that are present in real medical situations. Second, although all our participants had been trained in how to decide whether to withhold or withdraw treatment for critically ill patients, they are not ultimately responsible for making such decisions. In fact, such decisions are made during collegial meetings, which enable doctors to share their feelings and opinions. Finally, qualitative analyses of semistructured interviews with residents who have been involved in such difficult decisions would provide a better understanding of what residents think when they make them.

*Two multinomial logistic regressions were performed by regressing the residents' decision on the Agency index, and on the Experience index. The residents' perception of the patient did not influence significantly their decision (Agency: $-2 L L=-59.00$, $\mathrm{X}^{2}(2)=2.85, p=0.241$; Experience: $2 L L=-58.20, \mathrm{X}^{2}(2)=4.46$, $p=0.107)$.
The present study, carried out in France, where physicians have a legal obligation to respect patients' ADs refusing lifesustaining treatment, ${ }^{1}$ provides new insights into the issue of decision making in ICUs. Our finding that including personal information in an $\mathrm{AD}$ led more residents to postpone decisions on whether to stop treatment suggests that such information could make it more difficult for physicians to respect patients' wishes, as they are now required to do by French law. However, this information did not increase the likelihood a resident would consult the patient's family. Hence, promoting shared decision making by including the incapacitated patients' families in treatment decisions ${ }^{26}$ is a major challenge, especially in countries such as France, where ADs are legally binding.

\section{Author Disclosure Statement}

No competing financial interests exist.

\section{References}

1. Ministére des Affaires Sociales et de la Santé: Arrêté du 3 août 2016 relatif au modéle de directives anticipées prévu á l'article L. 1111-11 du code de la santé publique. J Officiel 2016;0181.

2. Pennec S, Monnier A, Pontone S, Aubry R: End-of-life medical decision in France: A death certificate follow-up survey 5 years after the 2005 act of parliament on patients' rights and end of life. BMC Palliative Care 2012: $11 ; 25$.

3. Lesieur O, Leloup M, Gonzalez F, et al.: Withholding or withdrawal of treatment under French rules: A study performed in 43 intensive care units. Ann Intensive Care 2015; 5:56.

4. Albarracin D, Ducousso-Lacaze A, Cabasson S, et al.: Advanced directives in an old patient with suicide attempt: Analysis of ICU physicians perception. Ann Intensive Care 2016;6(Suppl.1):245.

5. Horn R: The 'French exception': The right to continuous deep sedation at the end of life. J Med Ethic 2017. DOI: 10.1136/medethics-2017-104484.

6. Visser M, Deliens L, Houttekier D: Physician-related barriers to communication and patient- and familycentered decision-making toward the end of life in intensive care: A systematic review. Crit Care 2014;18: 604. 
7. Centofanti J, Swinton M, Dionne J, et al.: Resident reflections on end-of-life education: A mixed-methods study of the 3 wishes project. BMJ Open 2016;6:e010626.

8. Cook D, Swinton M, Toledo F, et al.: Personalizing death in the intensive care unit: The 3 wishes project. Ann Intern Med 2015;163:271-279.

9. Haque OS, Waytz A: Dehumanization in medicine: Causes, solutions, and functions. Perpect Psychol Sci 2012;7:176186.

10. Haslam N: Dehumanization: An integrative review. Pers Soc Psychol Rev 2006;10:252-264.

11. Haslam N, Loughnan S: Dehumanization and infrahumanization. Annu Rev Psychol 2014;65:399-423.

12. Kumar V, Abbas AK, Fausto N, Aster J (eds): Robbins and Cotran Athologic Basic of Disease, 8th edition. Philadelphia: Saunders/Elsevier, 2009.

13. Lammers J, Stapel DA: Power increases dehumanization. Group Process Intergroup Relat 2011;14:113-126.

14. Schulman-Green D: Coping mechanisms of physicians who routinely work with dying patients. Omega (Westport) 2003;47:253-264.

15. Trifiletti E, Di Bernardo GA, Falvo R, Capozza D: Patients are not fully human: A nurse's coping response to stress. J Appl Soc Psychol 2014;44:768-777.

16. Cole TR, Carlin N: The suffering of physicians. Lancet 2009;374:1414-1415.

17. Gray HM, Gray K, Wegner DM: Dimensions of mind perception. Science 2007;315:619.

18. Haslam N, Stratemeyer M: Recent research on dehumanization. Curr Opin Psychol 2016;11:25-29.

19. Rudski JM, Herbsman B, Quitter ED, Bilgram N: Mind perception and willingness to withdraw life support. Neuroethics 2016;9:235-242.
20. Albarello F, Rubini M: Reducing dehumanization outcomes towards Blacks: The role of multiple categorization and of human identity. Eur J Soc Psychol 2012;42:875882.

21. Harris LT, Fiske ST: Dehumanizing the lowest of the low. Neuroimaging responses to extreme out-groups. Psychol Sci 2006; 17:847-852.

22. Haslam N, Bain P, Douge L, et al.: More human than you: Attributing humanness to self and others. J Pers Soc Psychol 2005;89:937-950.

23. Stephan E, Liberman N, Trope Y: The effects of time perspective and level of construal on social distance. J Exp Soc Psychol 2011;47:397-402.

24. Williams LE, Bargh JA: Keeping one's distance. The influence of spatial distance cues on affect and evaluation. Psychol Sci 2008;19:302-308.

25. Milgram S: Obedience to Authority: An Experimental View. London: Tavistock Publications, 1974.

26. Kon AA, Davidson JE, Morrison W, Danis M: Shared decision making in ICUs: An American college of critical care medicine and American thoracic society policy statement. Crit Care Med 2016;44:188-201.

Address correspondence to: Stéphane Jouffre, PhD

Centre de Recherches sur la Cognition et

l'Apprentissage (UMR CNRS 7295)

MSHS Bâtiment A5 - 5 rue T. Lefebvre TSA 21103

F-86073 Poitiers cedex 9

France

E-mail: stephane.jouffre@univ-poitiers.fr 